\title{
ARQUITECTURAS PARA LA SOLEDAD. PROLIFERACIÓN Y PANDEMIA DE CAPILLAS AISLADAS [VERSIONES CHILENAS]
}

Arquiteturas para a solidão. Proliferação e pandemia de capelas isoladas [versões chilenas]

Architectures for solitude. Proliferation and pandemic of isolated chapels [chilean versions]

José Joaquín Parra-Bañón

Escuela Técnica Superior de Arquitectura, Universidad

de Sevilla. Sevilla, España.

jjpb@us.es

http://orcid.org/0000-0002-2147-0306

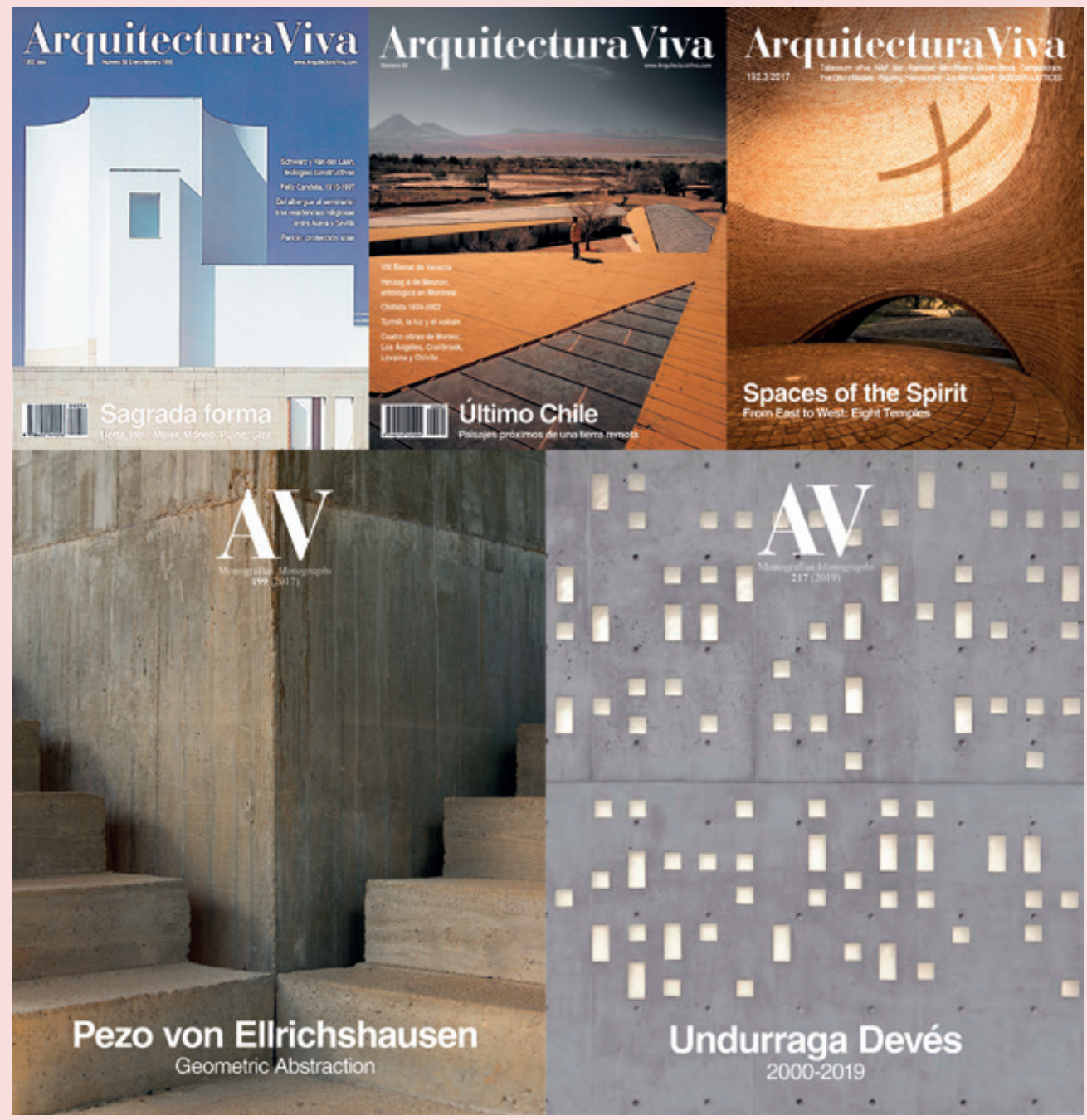

Espacios para el espiritu solitario. Cinco portadas editadas entre 1998 y 2019 .

uente: Luis

Fernández-Galiano, con referencias a obras chilenas, citadas en "Arquitecturas para la soledad". Composición del autor a partir de: Arquitectura Viva no $58,85,192$ y Monografí 192 y y 217 . 


\section{RESUMEN}

"Arquitecturas para la soledad" (aquella de reducidas dimensiones que primero fue usada por un solo residente y después habitada por una mínima cantidad de personas como lugar de retiro espiritual o ámbito de ritos litúrgicos) se ocupa de analizar las circunstancias y causas del gran incremento del número de capillas aisladas que se han proyectado y construido en las dos primeras decenas del siglo XX en el orbe, y particularmente en Europa y en Latinoamérica. El estudio de tal proliferación porcentual se centra, a modo de ejemplo y de síntoma, en un reducido repertorio de obras proyectadas por arquitectos chilenos. Metodológicamente (aunque el avance que se presenta solo contenga algunos indicios de los procedimientos utilizados), el estudio se llevará a cabo revisando las páginas y portadas que les dedican las publicaciones de arquitectura, impresas o digitales, recurriendo a las estrategias discursivas de los análisis de los tipos arquitectónicos y a la semántica, a la comparación y al cálculo estadístico, a la potencialidad comunicativa de la imagen fotográfica y a la capacidad expresiva de la palabra. A partir de las tesis planteadas se propone que se redefina el término capilla para resignificarlo; de los casos presentados, que el heterogéneo repertorio formal de la contemporaneidad parte de lo vernáculo para aventurarse en la experimentación carente de prejuicios. Los datos, finalmente, permiten deducir que el auge actual de las arquitecturas eremíticas está relacionado con las circunstancias de las sociedades urbanas hegemónicas, así como pronosticar que el proceso se verá acelerado por las situaciones pandémicas venideras.

Palabras Clave: Soledad, capilla, Eduardo Castillo, Pezo-von Ellrichshausen, Smiljan Radić

\section{RESUMO}

"Arquiteturas para a solidão", aquelas de dimensões reduzidas inicialmente utilizadas por um único residente e, mais tarde, utilizadas por um número mínimo de pessoas como locais de retiro espiritual ou âmbitos de ritos litúrgicos, trata da análise das circunstâncias e causas do grande aumento da quantidade de capelas isoladas que foram projetadas e construídas nas duas primeiras décadas do século XX no mundo e, particularmente, na Europa e na América Latina. O estudo dessa proliferação percentual foca-se, a título de exemplo e sintoma, em um repertório reduzido de obras de arquitetos chilenos. Metodologicamente, embora os avanços apresentados contenham apenas alguns indícios dos procedimentos utilizados, o estudo será realizado através da revisão das páginas e capas a elas dedicadas por publicações de arquitetura, impressas ou digitais, recorrendo às estratégias discursivas da análise dos tipos arquitetônicos e à semântica, à comparação e ao cálculo estatísticos, ao potencial comunicativo da imagem fotográfica e à capacidade expressiva da palavra. A partir das teses levantadas, propõe-se que o termo capela seja redefinido para ressignificá-lo e que, dos casos apresentados, o repertório formal heterogêneo da contemporaneidade parte do vernáculo para se aventurar na experimentação desprovida de preconceitos. Os dados, por fim, permitem deduzir que o atual auge das arquiteturas eremíticas responde às circunstâncias das sociedades urbanas hegemônicas, além de permitir antever uma aceleração do processo devido às futuras situações pandêmicas.

Palavras-Chave: Solidão, capela, Eduardo Castillo, Pezo-von Ellrichshausen, Smiljan Radić.

\section{ABSTRACT}

"Architectures for solitude", which are those that are small in size and were first used by a single resident to later be inhabited by a very small number of people as a place of spiritual retreat or for liturgical rites, deals with analysing the circumstances and causes of the great increase in the number of isolated chapels that have been projected and built in the first two decades of the 20th century around the world, and particularly in Europe and Latin America. The study of such a notorious proliferation focuses, by way of example and symptom, on a reduced repertoire of works designed by Chilean architects. Methodologically speaking, although the progress presented only contains some indications of the procedures used, the study will be carried out by reviewing the pages and cover pages dedicated to them by architecture publications, printed or digital, resorting to the discursive strategies of architectural types and semantics analysis, comparison and statistical calculation, the communicative potential of the photographic image, and the expressive capacity of the word. From the theses raised, it is proposed that the term "chapel" be redefined to re-signify it; of the cases presented, that the heterogeneous formal repertoire of contemporaneity starts from the vernacular to venture into experimentation devoid of prejudice. Ultimately, the data allow us to deduce that the current rise of hermitic architectures is related to the circumstances of hegemonic urban societies, as well as to predict that the process will be accelerated by upcoming pandemics.

Keywords: Solitude, chapel, Eduardo Castillo, Pezo-von Ellrichshausen, Smiljan Radić. 


\section{INTRODUCCIÓN}

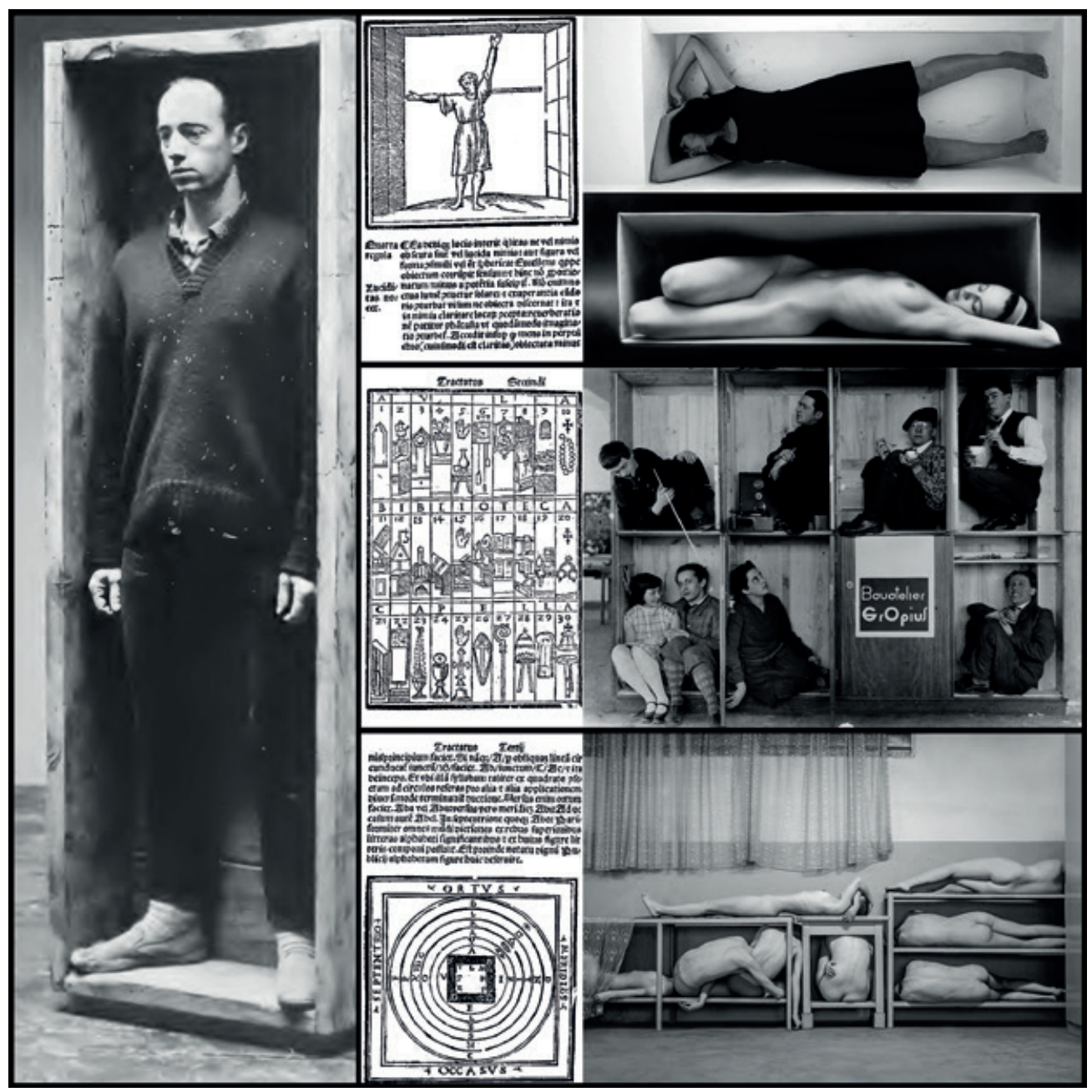

Figura 1

Cajas-casascapillas-

celdas-ermitas-

habitaciones: Robert Morris, Autorretrato 1958. Congestorium artificiose memorie, 1553. Ana Díez, Hueco 2011. Ruth Bernard, Box 1962. Edmund Collein Bauhaus 1928|Evelyn Bencicova, Ecce Homo 2015.

Fuente: Composición del autor. 


\section{CONTEXTUALIZACIÓN. AISLAMIENTO EREMÍTICO, CONTEMPORANEIDAD Y PARTICULARIDADES CHILENAS}

Como un preludio o premonición de las transformaciones que en el 2020 comenzaron a suceder en el orbe aceleradas por las epidemias, la arquitectura de la soledad y de la clausura, obligada por la necesidad de distanciamiento, forzada por la imposición de aislamiento social y ambiental que exigen políticamente las zoonosis pandémicas, lleva dos décadas de auge creciente, de incremento exponencial, de experimentación a partir tanto de las propuestas del Movimiento Moderno como de los hallazgos de la arqueología. Los departamentos, mínimos hasta la estenosis, que ofrecen como modelos residenciales del futuro los promotores inmobiliarios, los dormitorios jibarizados hasta convertirlos en capsulas o en capullos de seda oriental, las cajas consideradas habitaciones o los museos, como los ya ensayados en Coímbra para mostrar una única obra, y con capacidad para un solo espectador, son indicios de la teoría que fundamentará el paradigma de la arquitectura que se avecina [Figura I].

De todas las arquitecturas elementales que se ocupan de imponerles límites y fronteras a las personas, de confinarlas en un espacio vital cada día más reducido, de angustiarlas aproximando las paredes hasta el contacto con las yemas de los dedos de los habitantes constreñidos (Romberch, I553; Parra, 2019), quizá ninguna tan significativa ahora como aquella que comenzó su andadura con el modelo residencial que en la antigüedad, por estar situadas en lo yermo, llamaban ermita (Sevilla, 2000) (Vorágine, 1997). Es decir, con la guarida del ermitaño, con el cobijo desterrado que, con el paso del tiempo, dará lugar a lo que hoy, genérica e imprecisamente, denominamos capilla (Sadeler, 1594). En el recinto individual para el retiro solitario y silencioso vinculado a las primeras iniciativas ascéticas, donde la celda (cueva o cabaña, antro o simple cobertizo de rocas y ramas) es una habitación mínima y huera, está enraizada la tipología religiosa de las capillas exentas, independientes, autónomas, aunque no la de las capillas integradas en otros edificios de los que dependen funcionalmente.

Salvo como referencias, no se ocupa este artículo de las capillas que definen los diccionarios como edificios contiguos a una iglesia, o que son parte integrante de ella: no de las que son un fragmento formal y orgánicamente dependiente de otro edificio, sea este un templo o un palacio; ni de aquellas en las que hay implícita una relación de sumisión dimensional entre los componentes, sino de las que se han escindido jerárquica y espacialmente de un organismo superior. Es decir, de las capillas herederas de aquellas que eran edificaciones aisladas y desocupadas, de pequeño tamaño y levantadas con cierta elementalidad constructiva y estructural; en general anónimas, económicas, sólidas, sostenibles y de fácil mantenimiento, integradas en el medio ambiente, radicadas en lo despoblado, y que eran de titularidad comunal. Las que solían constar de un solo recinto, de un único espacio interior que era usado como templo: 
para acoger extraordinariamente ciertos ritos -individuales o comunitarios- de la liturgia cristiana. Los usuarios, y no los intermediarios, como Diógenes con la tinaja en la que vivía, eran los que se ocupaban de su conservación. Aquellas ermitas primitivas, una vez que perecieron y fueron considerandos santos sus antiguos moradores, después de que fueran canonizados los ermitaños constructores y residentes, dejaron de ser moradas de un solo ámbito y se transformaron en lugares de veneración. La casa entonces se transformó en templo: y el interior doméstico se convirtió, por el uso y el rito, por la imposición de otros hábitos y la inclusión de nuevas ceremonias, en un interior sacro.

Ya los grandes maestros del Movimiento Moderno, sin olvidar los precedentes grecolatinos y bizantinos, los medievales del Camino de Santiago o los magníficos ejemplares del Renacimiento europeo, levantaron espléndidas capillas que eran, en realidad, pequeñas iglesias: Mies van der Rohe, Capilla en el ITT, Chicago, 1952; Eero Saarinen, Capilla en el MIT, Boston, 1954 (Lambert, 200I) (Merkel, 20I4). Y levantaron iglesias, a las que continuaron Ilamando capillas, aunque algunas tuvieran pretensiones de catedral (Lloyd Wright, Annie Pfeiffer Chapel, Lakeland, 1941; Le Corbusier, Chapelle Notre Dame du Haut, Ronchamp, 1955), y humildes capillas conventuales (Luis Barragán, Capilla de las Capuchinas Sacramentadas, México DF, 1952-60) de las que tanto aprendieron nuestros contemporáneos (Tadao Ando, Capilla de la Luz, Osaka, 1989) [Figura 2].

Que la proliferación ecuménica de capillas ha iniciado uno de sus periodos álgidos en las últimas décadas, de oriente a occidente, lo constata la feraz experimentación realizada con todas las formas arquitectónicas concebibles, desde las extravagancias espirales de Hiroshi Nakamura (Capilla Ribbon, 2013) hasta la serenidad metafísica de la proyectada por Zhang Lei (Nanjing, 20।4), incluida la monolítica Capilla Bruder Klaus de Peter Zumthor (Wachendorf, 2007) o la más reciente y acogedora de Bernardo Bader (Capilla Salgenreute, 2016).

No todas fueron consagradas ni fueron proyectadas para acoger los ritos religiosos que la tradición les tenía asignados. Esa es una de las singularidades de las capillas contemporáneas: la omisión de lo sagrado y la prescindencia de los rituales que antes las caracterizaban y que las distinguían de, por ejemplo, los meros lugares de meditación. Hoy se denomina capilla indistintamente a los espacios de culto cristiano y a los espacios para la reflexión, a las áreas de descanso y a las áreas de reposo del caminante y del ciclista, sean estos devotos peregrinos o se trate de esforzados deportistas urbanos (Parra, 2020).

De los años transcurridos del siglo es 2018, según los datos recopilados, y aún inéditos, por el Departamento de Expresión Gráfica Arquitectónica de la Universidad de Sevilla en una de las investigaciones en curso dirigidas por el autor de este artículo, el 
Figura 2

Cuatro capillas

siglo XX: Mies van

der Rohe, Capilla

ITT, 1952. Eero

Saarinen, Capilla

MIT, 1954. Luis

Barragán, Capilla

de las Capuchinas,

1960. Tadao Ando,

Capilla de la Luz

1984 .

Fuente: composición

del autor. más pródigo en la construcción e inauguración de capillas en el ámbito de la Comunidad Europea. Quizá sea suficiente una gavilla de indicadores para avalar tal afirmación. En 2018 el estado del Vaticano se presentó por primera vez en una Bienal de Arquitectura de Venecia: lo hizo con diez capillas expresamente construidas para tal ocasión. También en 2018, en Alemania, la Fundación Siegfried y Elfriede Denzel construyó las tres primeras capillas del programa "Sieben Kapellen": de una de estas, de la armada en Unterliezheim, se encargó John Pawson. Ese año, en el Algarve portugués, Álvaro Siza concluyó la construcción de la que, por su discreción y su sabia humildad, es una de las capillas más honestas de entre las recientes

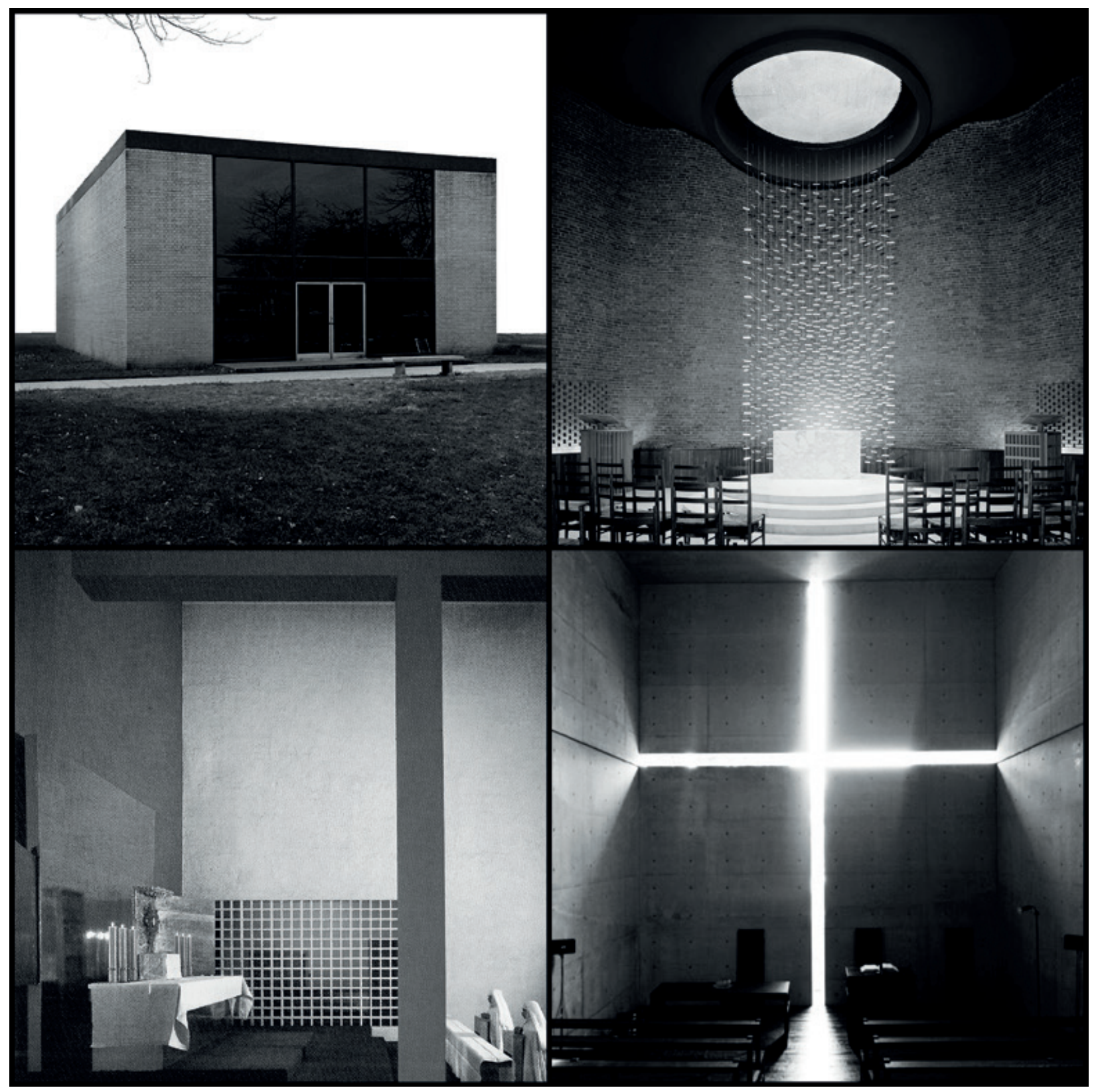

AS / Vol. 39. No59 / ENERO 2021 // ISSN impresa 07 |6-2677 / ISSN digital 0719-6466 


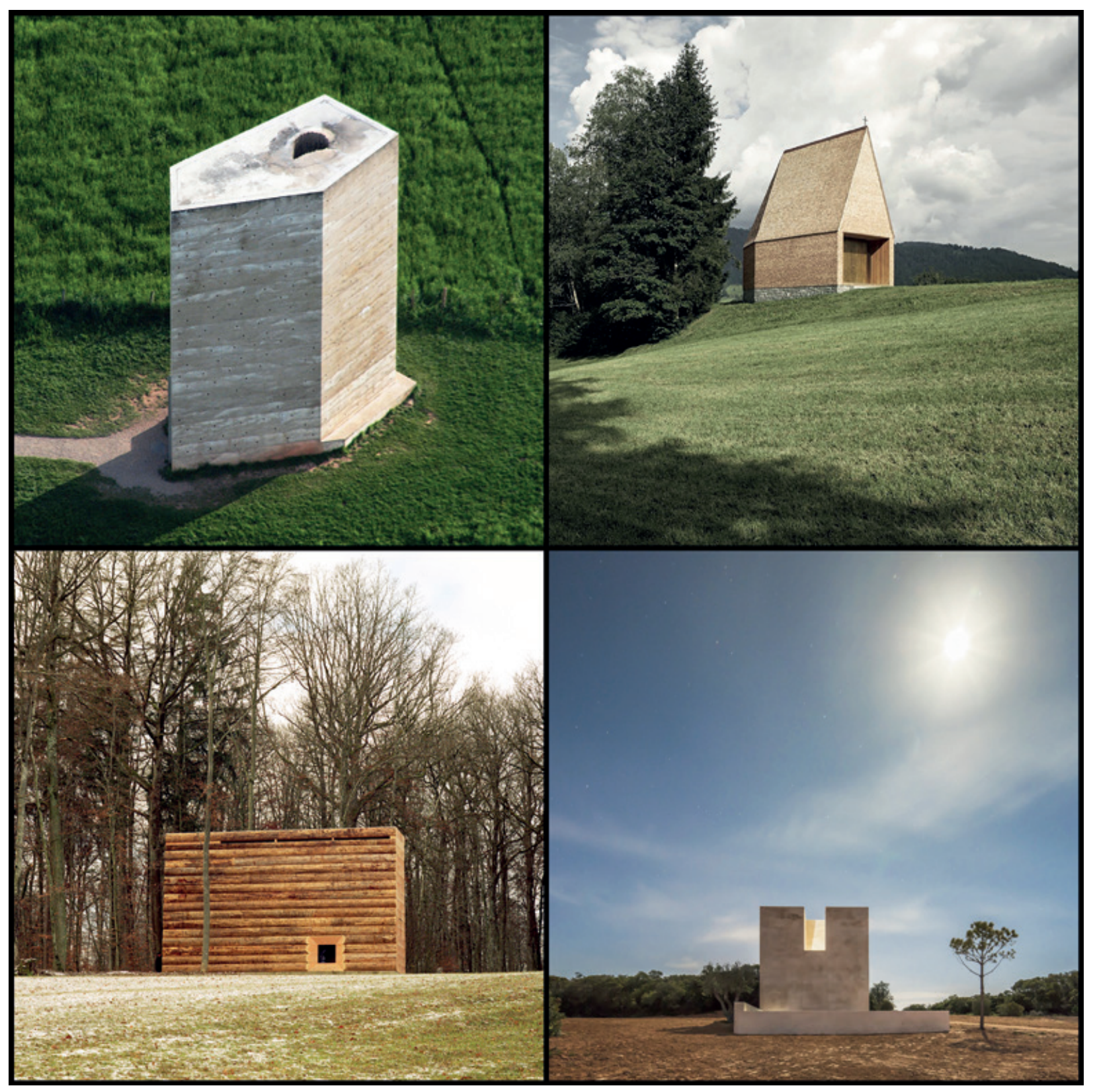

Figura 3

Cuatro capillas

siglo XXI: Peter

Zumthor, Wachendorf

2007. Bernardo

Bader, Salgenreute

2016. John Pawson,

Álvaro Siza, Lagos

2018 .

Fuente: Composición

del autor.
[Figura 3]. Asimismo, se prodigaron los concursos internacionales acerca de esta temática, como fue el propuesto por la multinacional de la Cerámica Hispalyt: una Capilla en el Camino de Santiago que se izaría en Palencia.

Ni Latinoamérica en su conjunto, ni Chile en particular, quedaron al margen de esta tendencia universal, que ha fecundado a todas las confesiones religiosas vigentes, y contaminado a todos los movimientos espirituales ansiosos de trascendencia y de mística. Desde las capillas australes de Chiloé, clavadas para siempre en la humedad del suelo inestable, o trasladadas de un sitio a otro mediante la práctica excepcional de la "tiradura", un mismo hilo trenzado enhebra esta arquitectura 


\section{METODOLOGÍA}

\section{INCERTIDUMBRE, TIPOLOGÍA Y} COMPARATÍSTICA patrimonial con la arquitectura sincera y frágil de las capillas marginales de las "animitas" y, por ejemplo, con la "Capilla de la Crucifixión", levantada en Venecia por Smilan Radić. De esa misma cuerda, como sucede en los ábacos que se muestran en el sótano del Museo Chileno de Arte Precolombino, pendía en 2018 el "Concurso Nueva Capilla País" promovido por la Escuela de Arquitectura de la PUC de Chile, que tenía el propósito de levantar una red con unas cincuenta de ellas en las comunidades más rezagadas de Chile, y a aquella están atadas, entre otras, las elocuentes capillas del Monasterio Benedictino de la Santísima Trinidad proyectadas por los monjes-arquitectos Gabriel Guarda y Martín Correa (1964) y la capilla de hormigón que la arquitecta Cazú Zegers curvó en Puente Alto en 2003. Y también, aunque la distancia desde el último nudo a la cuerda de unión del quipú sea mayor, la Capilla del Retiro de Undurraga-Deves (2009) o, por otras razones, el pabellón-capilla de Pezo-von Ellrichshausen en Vitry-Sur-Seine (2017).

El estudio orientado a determinar en qué medida la multiplicación de estas arquitecturas ensimismadas está siendo incentivada por la incertidumbre de una cultura y una población que se siente desorientada, y quizá abandonada a su precario destino biológico, o cómo es promovida por el miedo cerval que en ella suscitan las crisis medioambientales, tanto las climatológicas como sanitarias, debería de interesarle más a las disciplinas arquitectónicas, aunque la investigación científica de su fenomenología no sea de su estricta competencia. De ahí que en el estudio del que aquí se informa (en desarrollo por el autor, en el grupo de investigación "TEP3939-Arquitecturas para la ciudad creativa") se propongan análisis anamnésicos que permitan confeccionar un historial a partir de la memoria con la intención de desvelar la etiología del problema, que indagan en la casuística rastreando indicios y manifestaciones del trauma, detectando síntomas para, a través del proyecto, plantear respuestas arquitectónicas que, en definitiva, buscan colaborar propositivamente, desde la habitación a la ciudad y al territorio, en la solución global del conflicto que se avecina.

En este avance se recurre a la semántica y a la etimología para hurgar en los significados; se confía en la metodología comparantista ya experimentada por los lingüistas persiguiendo similitudes y diferencias entre los casos de estudio seleccionados y se omite, estratégica y temporalmente, la cuantificación y la geolocalización de los mismos al tiempo que, atenazados por la brevedad, estos son aislados de sus contextos. Las pesquisas estadísticas que fundamentan las tesis aquí planteadas se han realizado indagando en la información registrada en publicaciones periódicas, digitales o impresas, y en monografías y antologías especializadas en arquitectura eclesiástica, así como en actas congresuales. Sirva como sintomatología de la creciente atención que los medios les vienen prestando a estas arquitecturas el que en 2002 la revista Arquitectura Viva ( $\left.n^{\circ} 85\right)$ dedicara un monográfico a Chile en el que publicó la Capilla del Recuerdo de Eduardo Castillo seguida de la Iglesia del Colegio 


\section{CAPILLA DE NAMA Y CAPILLA DEL RETIRO (NAMA: AUCO)}

Villa María de Enrique Browne y de la Catedral de Nuestra Señora en Los Ángeles, de Rafael Moneo. Antes, en 1998, el volumen n 58 se tituló "Sagrada Forma" (Fernández-Galiano, 1998), documentando divergentes ejercicios formales realizados en iglesias por Botta, Holl, Meier, Moneo, Piano y Siza, mientras después, en 2017, la serie capilla-iglesia-catedral dio paso al monográfico titulado "Spaces of the Spirit. From East to West: Eight Temples", donde exhibía ocho edificios, situados en cuatro continentes, a los denominaba unas veces "templos" y otras "espacios del espíritu” (Fernández-Galiano, 2017a). Esta revista disciplinar, al igual que El Croquis o que The Architectural Review, han destacado, del catálogo general de sus obras, situándolas en las portadas, las capillas, los oratorios, los camarines, las basílicas y los sagrarios de los maestros actuales, de Peter Zhumtor y John Pawson, de Álvaro Siza y de Bernardo Bader, por citar a cuatro europeos señeros de diversas generaciones. En las plataformas digitales de arquitectura hegemónicas, sucede prácticamente lo mismo: evidencian que entre las arquitecturas más publicitadas en las últimas décadas figuran los "lugares para la meditación personal".

La humilde Capilla de la Santa Cruz de Nama es una verdadera capilla. La premiada Capilla del Retiro proyectada por la oficina Undurraga-Deves, al igual que la Capilla de San Alberto Magno de Requesens y Pávez (Valparaíso, 2014), no es, léxica o semánticamente, una capilla: es una iglesia más o menos grande. Una iglesia que, por sus dimensiones y debido a la complejidad de su programa, no esconde su ambición de santuario, o de basilica. Ambos edificios son, en cualquier caso, templos. La Capilla de Nama, en la Quebrada de Suca, en la comuna de Carmiña, en la región de Tarapacá, a 3013 metros sobre el nivel del mar, es una acogedora nave construida con adobe y cubierta con una techumbre de barro y de paja. Quizá edificada en los tiempos primordiales de la fundación del pueblo, tiene una superficie de apenas $35 \mathrm{~m}^{2}$. Su elementalidad es aparente: es un organismo arquitectónico complejo y, con toda probabilidad, perfecto. Cercada por un muro bajo, ocupa el corazón de un rectángulo de aproximadamente 19 metros de largo y 9 de ancho. A la izquierda, el campanario: el armazón que sustenta las dos campanas domésticas. Enfrente, la puerta azul, enmarcada en un pórtico de una austeridad y de una belleza conmovedoras. La puerta, la portada, el pórtico se abre al final del atrio: la cubierta sobresale y, apoyada en los dos muros emergentes, delimita un espacio intermedio que acoge y abraza al feligrés del mismo modo que lo hace la Columnata de Bernini en la Basilica de San Pedro del Vaticano, pero aquí sin atemorizarlo. Blanca, encalada, con su hornacina votiva, recortada contra las montañas cónicas y ásperas, la Capilla de Nama bien podría estar en vez de en el Altiplano chileno, encumbrada en una isla mediterránea. Le Corbusier, Sert, Coderch, Rudofsky y tantos otros autores sensibles con lo que carece de pedigrí, la habrían admirado (Rudofsky, 1964).

La Capilla del Retiro se hunde excavada a los pies del Monte Carmelo, tras el Monasterio Carmelita de Auco, al lado de la casa de huéspe- 
Figura 4

Cuatro capillas

chilenas: Capilla

de la Santa Cruz de

Nama, 1856. Guarda

Y Correa, Capilla

Santísima Trinidad,

1964. Requesens y

Pávez, Capilla de

San Alberto Magno,

2014. Undurraga y

Devés, Capilla del

Retiro, 2009.

Fuente: Composición

del autor des del complejo residencial, al cual presta servicio (Fernández-Galiano, 2019). Construida en 2009 con cuatro musculosas pantallas de hormigón, revestida por el interior con traviesas de madera recicladas, ocupa una superficie construida de $620 \mathrm{~m}^{2}$. Es, qué duda cabe, un buen proyecto que, probablemente, seguiría siendo meritorio si acogiera un auditorio, una biblioteca, un gran gimnasio o un centro comercial para las élites. No es una capilla debido a su tamaño, a su magnificencia, a su heterogeneidad y a su necesaria complejidad programática: sí lo es por su dependencia administrativa del Monasterio de Auco, como también lo es la Capilla Sixtina respecto a la Basilica de San Pedro o lo es, en Florencia, la Capilla Pazzi, con la que se despidió del mundo habitable el maestro Brunelleschi [Figura 4].

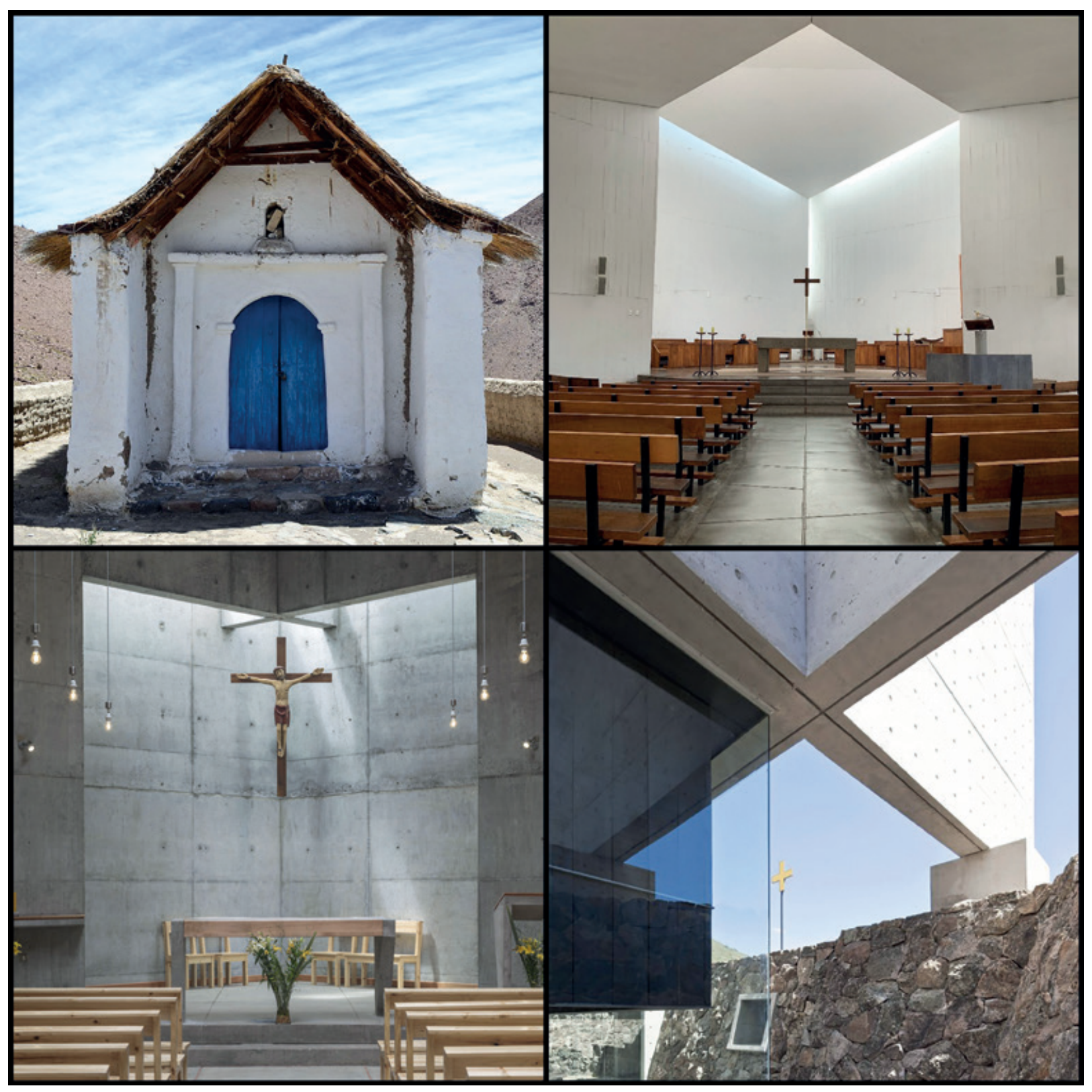

AS / Vol. 39. No59 / ENERO 2021 // ISSN impresa 07 I 6-2677 / ISSN digital 07 I9-6466 


\section{CAPILLA L'ANIMITA Y CAPILLA BELL (CONCEPCIÓN: VITRY-SUR-SEINE)}

Las capillas diseminadas a lo largo de los caminos chilenos para recordar a los muertos que allí perecieron significando el lugar del deceso son, porque así son popularmente llamadas, capillas. Las "capillas de las animitas" contienen cigarros, palabras, exvotos, fotografías, muñecos, flores, fuego, pero nunca capellanes ni ermitaños: tampoco fieles. Las "animitas" se denominan tradicionalmente capillas porque la palabra altar y la palabra monumento les parecieron grandilocuentes a sus fundadores, excesivas para nombrar a una arquitectura tan sucinta y germinal; porque "casa del ánima", "casa animada" o "casa de los espíritus", eran sintagmas demasiado poéticos para atribuírselos a una maqueta o a una arquitectura casi de juguete. "Casa del alma" denomina Eduardo Castillo (2002), en un artículo publicado en el número 85 de Arquitectura Viva, a la que proyectó para el municipio Florida, a la cual también llamará "Capilla del Recuerdo" "y "Capilla L'Animita" en conmemoración a las "animitas" populares. Estas son, ideológicamente, capillitas, templetes, sagrarios profanos, cenotafios diminutivos, luciérnagas, lámparas encendidas en la noche: aunque sean una simple pared, un grafiti, una tapia, una lápida o una oquedad, son arquitectura. Para que los universitarios no olviden que se trata de edificios, estas capillas tienen, miniaturizada, reducida a esquema, impresa en la piel, una casa simbólica: es la casa dibujada en los cuadernos infantiles y la que aparece en los sueños convencionales, la tallada en mármol por Louise Bourgeois y la que trazaba en la pizarra Juan Borchers en sus clases. La que construyó Castillo con tablas de madera junto a un camino de Concepción en el año 2000 es una verdadera capilla que brota de aquellas anónimas y colectivas: una capilla con características de ermita, con esencia de seno materno y de regazo afectivo, con peculiaridades de ámbito para el recogimiento. Una "capilla como una forma arquetípica, capaz de identificarse con lo sagrado" afirma en su último párrafo el artículo antes referido (Castillo, 2002, p. 53).

En Francia Mauricio Pezo y Sofía von Ellrichshausen proyectaron y construyeron en 2017 el denominado Bell Pavilion en los jardines del Musée D'Art Contemporain du Val-De-Marne, en Vitry-Sur-Seine, para cobijar sonidos reproducidos e imágenes en movimiento (Fernández-Galiano, 20 I7b). Este edículo de 50 m2, levando en unos días con bloques prismáticos sobre un pavimento preexistente, acogería la proyección de un video de que el artista Christian Boltanski había grabado en el desierto de Atacama en 2014 y que fue exhibido en la Bienal de Venecia en 2015. La obra, la filmación, se titula Animitas. Muestra una plantación de varillas metálicas rematadas por campanillas, cuyos badajos son impelidos, a través de una placa que cuelga de ellos, por el viento tórrido del desierto. El museo se refiere a la obra de los arquitectos como "capilla-pabellón", o como "oratorio-pabe\|ón". También llaman así a su criatura los propios autores, avezados en idear disímiles pabellones, al describir y argumentar su proyecto: le dicen capilla a esta sala de proyección cuando aluden a su naturaleza 


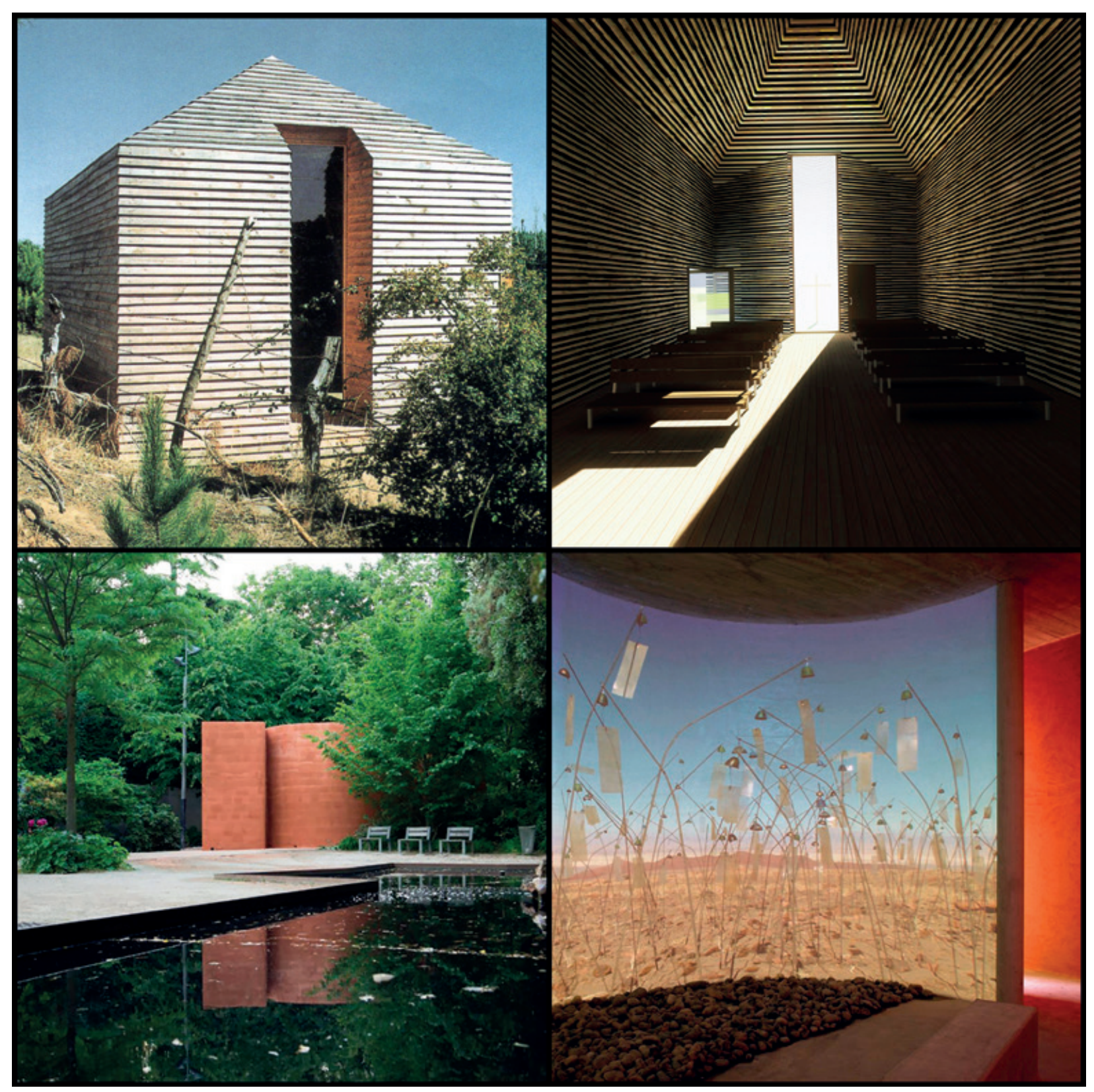

Figura 5

Dos capillas

animadas: Eduardo

Castillo, Capilla

del Recuerdo,

del Recuerdo,

Ellrichshausen,

Bell Pavilion,

2017.

Fuente: Composición

del autor. religiosa y al insistir en su carácter misterioso. Y uno y otra, al igual que Castillo, recuerdan su conocimiento de las "animitas" afirmando que en ellas está la semilla de este recinto oscuro y sinuoso, ocupado por un asiento en el que los visitantes pueden demorarse en la observación plástica de un horizonte sonoro trasfundido desde la inmensidad del paisaje de Chile al confinamiento de una habitación contemplativa [Figura 5].

La Capilla Bell no está lejos, por tanto, de la llamada Capilla Rothko, proyectada por Philip Johnson, Barnstone y Aubry, inaugurada 


\section{CAPILLAS BENEDICTINAS Y CAPILLAS VATICANAS (SANTIAGO DE CHILE: VENECIA)}

en Houston en 197I y hoy utilizada como museo, como sala de reuniones y conferencias (Johnson, 1979). La folie Pezo-von Ellrichshausen-Boltanski y el oratorio octogonal de Rothko, evidencian la aceleración en el proceso de disolución del concepto tradicional de capilla: cómo las arquitecturas para la contemplación se han convertido paulatinamente en arquitecturas para ser contempladas. La confusión terminológica también ha sido alentada por la soberbia, o por la arrogancia, de querer ponerle nombre a aquello que quizá no deba de tener un nombre que lo identifique, así como por los equívocos derivados de la teoría acerca de Los no lugares. Espacios del anonimato de Marc Augé (2000).

La infiltración de la arquitectura vernácula en la contemporánea a través de las "animitas" es manifiesta en este y otros proyectos chilenos de capillas candidatas a la vanguardia. Las capillas chilenas, muchas de las levantadas en los últimos años, tienen, además, reminiscencias y la impronta de las capillas y de la iglesia del Monasterio Benedictino de La Santísima Trinidad, proyectada en 1961 por los arquitectos, y monjes, Gabriel Guarda y Martín Correa, construida entre 1962 y 1964 en el Cerro Los Piques, en Santiago de Chile. La pregnancia y trascendencia de esta iglesia, que se puede denominar capilla tanto por depender orgánicamente de un monasterio como por contener en su interior otras sublimes capillas menores, es en algunos casos evidente $y$, en otras ocasiones, como en la italiana de Radić, perceptible solo en la sutileza de algunos detalles, o en la francesa de Pezo, reconocible en la fluidez del espacio. Así, en la Capilla de San Alberto Magno, el espacio cúbico y la diagonal evidencian sus vínculos con ella; en la sinuosa Capilla del Espíritu Santo de Cazú Zegers (La Colonia, 2003), las curvas de hormigón evitan la tangencia para introducir, como en Las Condes, aunque ahora contorsionadas, franjas de luz disolvente; y en la Capilla del Retiro, incluso la Cruz señalética que indica la rampa de acceso, se inspira en la Cruz del altar monástico.

Los recintos benedictinos de La Santísima Trinidad, la ambarina Capilla del Santísimo, al igual que la Capilla Cornaro de Roma, en la Iglesia de Santa María de la Victoria, están construidas con la luz dorada que emana de fuentes distintas a la del conocimiento. La Capilla Cornaro era solo una de las ocho capillas funerarias que se abrían convencionalmente a la nave hasta que Gian Lorenzo Bernini la fecundó esculpiendo, para recreo del cardenal que le hizo el encargo, a Teresa de Ávila, acompañada de un ángel, durante uno de sus conmovedores y más turbadores éxtasis.

Ajeno al caso ejemplar de las "animitas" y en las antípodas de las capillas benedictinas, en la decimosexta Bienal de Arquitectura deVenecia, en el otoño del 20 I 8, elVaticano, como estado participante, se presentó al mundo profano de la arquitectura con un muestrario de diez capillas recién concebidas. Este primer pabellón múltiple de la Santa Sede en una bienal veneciana se levantó disperso, atomizado, engarzado en una 
Figura 6

Cuatro capillas venecianovaticanas 2018: Eduardo Souto de Moura. Carla Juaçaba. Teronobu Fujimori. Javier Corvalán.

Fuente: Composición del autor. arboleda de la Isla de San Giorgio Maggiore. La Iglesia Romana reclutó, con la legítima intención de hacerse publicidad mediante la promoción arquitectónica, al chileno Smiljan Radić, al inglés Norman Foster y al portugués Eduardo Souto de Moura. También a Carla Juaçaba (Brasil); Javier Corvalán (Paraguay); Sean Godsell (Australia); Eva Prats y Ricardo Flores (España); Francesco Cellini (Italia); Andrew Berman (Estados Unidos) y Teronobu Fujimori (Japón). La selección del personal corrió a cargo de Francesco Dal Co [Figura 6]. Hubo algo de concurso, de casting, de competición estética entre ellas y sus estrellas.

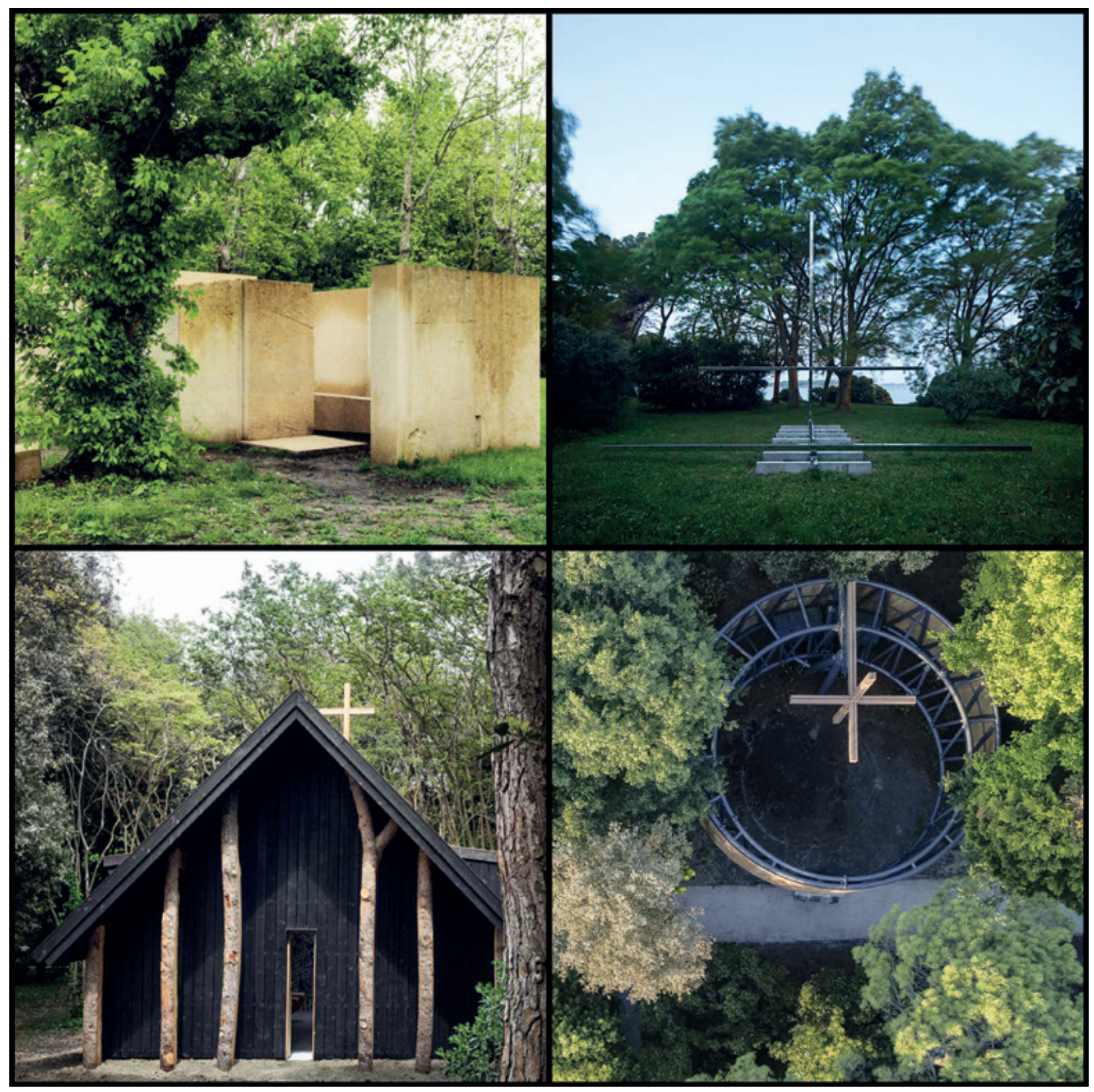

AS / Vol. 39. No59 / ENERO 202I // ISSN impresa 07 | 6-2677 / ISSN digital 07 |9-6466 


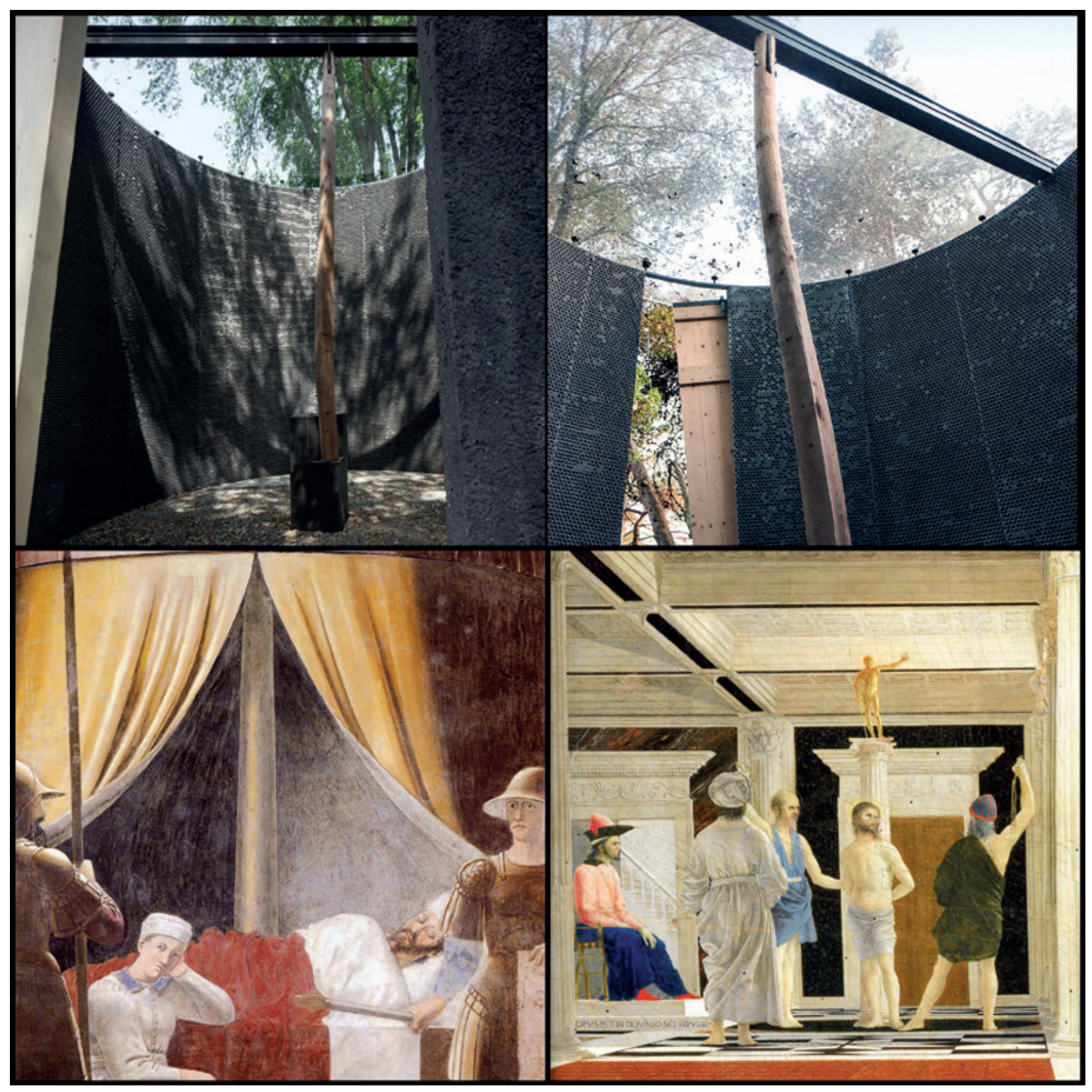

Figura 7

Cuatro fragmentos de una cruz:

Smiljan Radić,

Capilla de la

Piero della

Francesca. Detalles

de El sueño de

Constantino,

Flagelación, h.

1455 .

Fuente: Composición

del autor.
"Pabellones-capilla" los Ilamó con acierto Anatxu Zabalbeascoa (20/8). Pabellones porque eran artificios desmontables, transportables, como los de las primeras exposiciones universales, a otros lugares. Demasiado próximas unas de otras, visibles unas desde las otras, indiscretas y a veces estridentes, esas propuestas de relaciones entre espiritualidad profana y arquitectura religiosa, que son tan perceptibles y elocuentes tanto en una capilla románica como en una de las ortodoxas de las islas griegas, quedó, en la 
mayoría de los proyectos, limitada a pura escenografía. Ideadas para el alejamiento, resultaron demasiado simultáneas; pensadas para el desorden de la dispersión y de lo deshabitado, se organizaron en el agrupamiento y en la focalización teatral.

La capilla proyectada por Radić fue construida por la empresa Moretti utilizando ocho paneles curvos de hormigón, de 5 metros de altura, impreso mediante una matriz de burbujas de plástico, que forman un cilindro abierto y constituyen, al unísono, la estructura portante y el cerramiento del edificio (Márquez, 2019). Dos láminas rectangulares de vidrio doble, de 3 metros de ancho y 6 de largo, levemente inclinadas hacia una viga central que hace de canalón, sirven de cubierta transparente. Las ramas de los árboles, más que el cielo turbio de Venecia, se asoman al interior, a conversar con el tronco devastado que ocupa, como una columna central, el eje de ese espacio centrípeto.Tal vez ese mástil sea el madero vertical de la cruz, o stipes, y la viga metálica sea el travesaño horizontal, o patibŭlum, aunque solo son apreciables como una unidad cuando el observador levanta la vista. Tal vez la viga sea la viga maestra de la que hablan los textos bíblicos, aquella en la que se apoyan los místicos de los santorales. La Capilla de la Crucifixión se inspira, informan los comentaristas y refrenda el autor, en los altares votivos que son las "animitas" [Figura 7]. Otros espacios emocionales aquí reconocibles son los transparentes y angustiosos concebidos por Louise Bourgeois en sus células cilíndricas: en sus "Celdas", en las jaulas que componen la colección Estructuras de la existencia. La capilla vaticana de Radić también es una cabina atravesada por un espeto (un confesionario con un mudo y escuálido sacerdote de madera petrificado en medio: un dosel para una talla de Giacometti). Podría haber sido construida por una de las impresoras en tres dimensiones que durante la vigencia del covid- 19 se afanan en fabricar mascarillas.

En el volumen de $A R Q+2$ titulado Smiljan Radić. Bestiario, es posible encontrar varias fotografías, elegidas por el propio arquitecto para ilustrar sus poéticos textos, que también se podrían proponer como fundamentos de su proyecto. Por ejemplo, las de las arquitecturas compuestas con deshechos que documentan "Frágil fortuna" (Radić, 20|4a) o las pertenecientes a "La muerte en casa" (20|4b), e incluso las de las intervenciones de Gordon Matta-Clark o las de las obras de Frederick Kiesler. 


\section{CONCLUSIONES, DISCUSIONES, DIAGNÓSTICOS Y PRONÓSTICOS}

Ya que tergiversaciones conceptuales, acuciadas por la carencia de nombres precisos, condujeron a considerar "capillas" a edificios que no lo eran, tal vez hoy sea pertinente resignificar este término en el diccionario particular de la arquitectura en cuanto a edificación que apuesta por el aislamiento y la clausura, y que renuncia al concepto de feligresía y de iglesia (de espacio común), así como a la etimología de la palabra religión (re-ligare: re-unir) y, por tanto, proceder a redefinirlo, dado que la habitación es etimológica y funcionalmente el lugar en el que suceden los hábitos y donde acontecen los ritos, como habitación célibe en conflicto con la convivencia, apta para la vida en soledad. Una secuela de la identificación de la capilla con la vivienda mínima es el hecho de que en las capillas se estén ensayando formas de existencia efímera similares a las propuestas como formas de residencia habitacional, así como el fenómeno contrario: que el templo minúsculo imite a la casa monástica y el departamento se limite a eremitorio.

Considerados los precedentes, se puede pronosticar un incremento paradigmático en la producción de lugares en los que invocar a los dioses en solitario, de uno en uno o en pequeños grupos de devotos afines. La proliferación de espacios cerrados en los que encontrarse con la intimidad, en los que concentrarse en uno mismo, augura un regreso al monacato etimológico (al monasterio como monos-terion o residencia del hombre solitario), la vuelta a formas de convivencia basadas no en la casa compartida sino en el habitáculo monográfico: en la habitación como celda individual (frente a la que hay que descalzarse antes de entrar) o como célula indivisible e incomunicable conectada con el exterior telemáticamente. La gran diferencia entre la ermita genética y la capilla moderna es que entonces la soledad y la quietud eran elegidas, el aislamiento y la inacción voluntaria, y el silencio no era impuesto desde fuera sino ansiado desde dentro (Andrés, 2010). Que la búsqueda de ese estado era personal, volitiva, y no exigida por la acción política punitiva, y que la arquitectura respondía al deseo humano y no a la inclemente ley del mercado. La arquitectura para el escondimiento tiene, al parecer, un fructífero porvenir [Figura 8].

Así como en otras épocas predominaron los encargos, entre las arquitecturas singulares, de teatros o de museos, o de recintos docentes y de centros comerciales, en las dos últimas décadas la construcción de pequeñas arquitecturas públicas para la soledad (ermitas, capilla, oratorios, etc.) ha sufrido un singular aumento, cercano al 50\%, en el periodo 2000-2020 en el conjunto de países de la Comunidad Europea, al igual que en Latinoamérica, e incluso, particularizando por países, algo por encima de ese porcentaje en Chile y en Portugal. En el bienio 2019-2020, en la veintena de publicaciones analizadas, se han documentado el doble de proyectos y de obras relacionadas con la noción de templo que en el bienio 


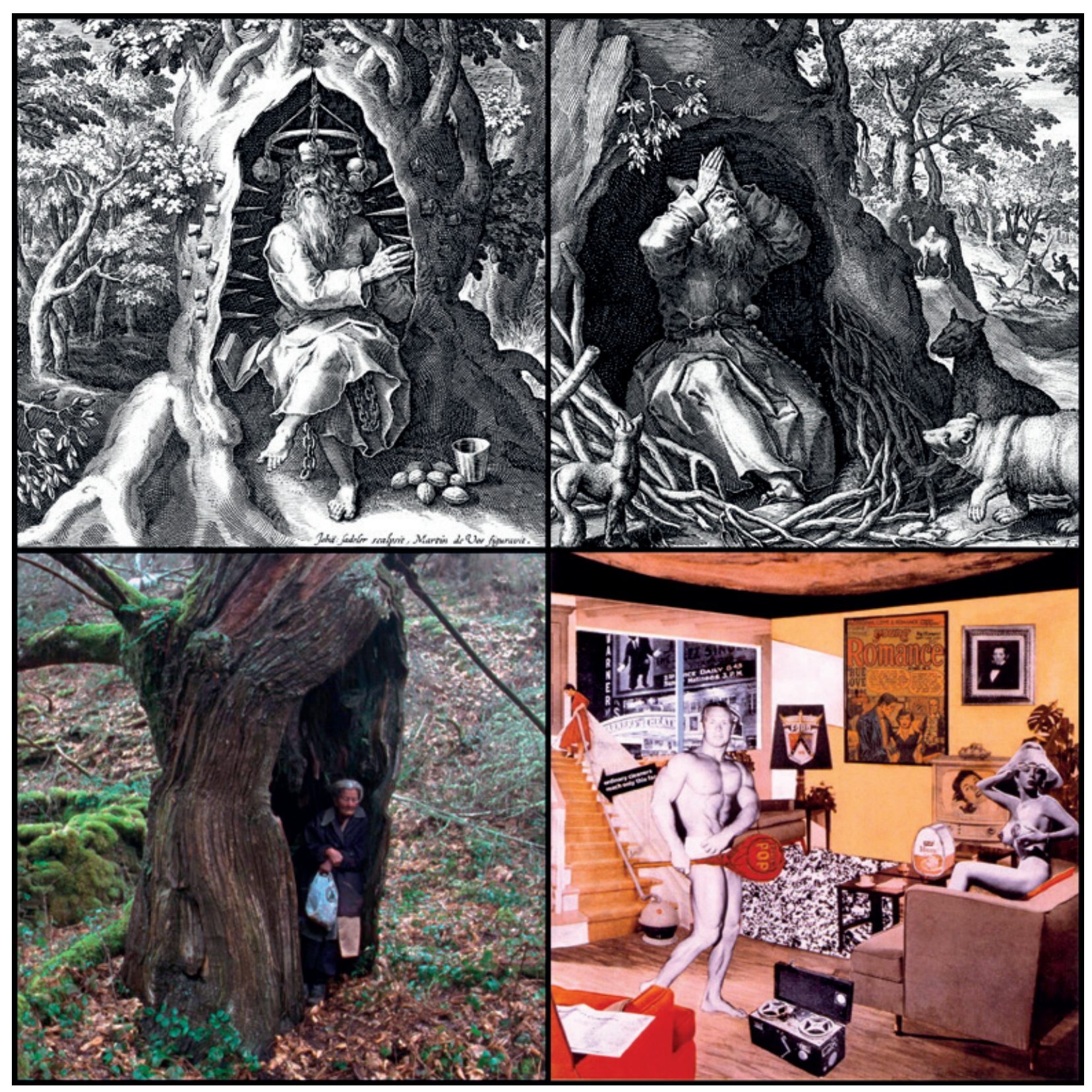

Figura 8

Eremitas: San

Zoerdade y san

Blasio grabados

por Jan Sadeler en

Sylvae Sacrae, 1594.

Fotograma de 0 que

arde, Oliver Laxe,

2019. Fragmento de

Richard Hamilton,

Fust what, 1956 .

del autor. 
1999-2000, construidos en los territorios referidos. Esta llamativa presencia en los medios de comunicación profesionales, con toda probabilidad, coincide con lo que sucede en la realidad material: aún no se concluido el cálculo de cuántos metros cuadrados de capilla por nación y por año se han edificado.

Esta expansión, fomentada por el miedo cerval a la extinción, se verá acelerada por las situaciones pandémicas, por la presente y las del porvenir, en las que las sociedades se disipan, las comunidades se disgregan y aíslan a sus componentes, se huye desde la ciudad al campo saludable, se aspira a lo deshabitado, se compite por el territorio privado y se retorna a formas de habitación experimentadas por los ermitaños que, como demostró Isidoro de Sevilla en sus Etimologías visigodas, con sus ermitas y sus eremitorios dieron lugar a los lugares trascendentes que luego se denominaron capillas. 


\section{REFERENCIAS BIBLIOGRÁFICAS}

ANDRÉS, R. (2010). No sufrir compañía. Escritos místicos sobre el silencio. Barcelona: Acantilado.

AUGÉ, M. (2000). Los no lugares. Espacios del anonimato. Barcelona: Gedisa. CASTILLO, E. (2002). La casa del alma: capilla en El Álamo, Florida. Arquitectura Viva, (85), 52-53.

FERNÁNDEZ-GALIANO, L. (Ed.). (1998). Sagrada Forma. Arquitectura Viva, (58), 3.

FERNÁNDEZ-GALIANO, L. (Ed.). (2017a). Spaces of the Spirit. From East to West: Eight Temples. Madrid: AV (192).

FERNÁNDEZ-GALIANO, L. (Ed.). (2017b). Pezo von Ellrichshausen. Geometric Abstraction. Madrid: AV Monografías (199).

FERNÁNDEZ-GALIANO, L. (Ed.). (2019). Undurraga Devés, 2000-2019. Madrid: AV Monografías (217).

JOHNSON, P. (1979). Philip Johnson, 1906-2005. Tokyo: A + U Publishing.

LAMBERT, P. (2001). Mies in America. New York: Canadian Centre for Architecture.

MÁRQUEZ, F. (Ed.). (2019). Smiljan Radić 2013-2019. El peso del mundo. Madrid: El Croquis.

MERKEL, J. (2014). Eero Saarinen. Londres: Phaidon Press.

PARRA, J. J. (2019). Arquitectura de la melancolía. Sevilla: Athenaica.

PARRA, J. J. (Ed.). (2020). Lugares ¿Qué lugares? Venecia: Edizione Ca' Foscari.

RADIĆ, S. (2014a). Frágil fortuna. Revista Ediciones ARQ+2, Smiljan Radić: Bestiario, 11-33.

RADIĆ, S. (2014b). La muerte en casa. Revista Ediciones ARQ+2, Smiljan Radić: Bestiario, 66-89.

ROMBERCH, J. H. (1553). Congestorium artificiose memorie. Venecia: Melchiorem Sessam.

RUDOFSKY, B. (1964). Architecture Without Architects. Nueva York: Museum of Modern Art.

SADELER, J. (1594). Sylvae Sacrae. Monumenta sanctiorus philosophie quam severa Anachoretarum.

SEVILLA, I. de (2000). Etimologías. Madrid: BAC.

VORÁGINE, S. de la. (1997). La leyenda dorada. Madrid: Alianza.

ZABALBEASCOA, A. (6 junio 2018). Tour por los pabellones-capilla del Vaticano en Venecia. Del tirador a la ciudad, El País. Recuperado de https://elpais. com/elpais/2018/05/29/del_tirador_a_la_ciudad/1527616380_814098.html 